\title{
Nerve-sparing high ligation of the inferior mesenteric artery with Cavitron ultrasonic surgical aspirator (CUSA)
}

\author{
C. G. S. Huscher ${ }^{1}$ A. Rossetti ${ }^{1,2}$
}

Received: 9 December 2016/Accepted: 11 December 2016/Published online: 20 January 2017

(c) Springer International Publishing AG 2017

Preservation of autonomic nerves to retain genitourinary function without compromise of oncologic clearance has been advocated for left colon and rectal cancer surgery $[1,2]$. However, there is still not much information on sexual and bladder function after the curative resection of sigmoid colon cancer [3, 4]. Autonomic nerve preservation during laparoscopic high ligation of the inferior mesenteric artery (IMA) can be difficult and challenging. Using conventional energy dissectors, it is very common to stay close to the autonomic nerves, and as a result, there is a high risk of damage. We therefore decided to perform a high dissection of IMA with CUSA which allowed a clear identification of the branches climbing up all around the IMA, starting from the hypogastric nerves. After the dissection with CUSA, it becomes easy to separate the IMA from the autonomic plexus at its origin and to preserve the nerve anatomy while performing a high ligation.

\section{Compliance with ethical standards}

Conflict of interest The authors declare that they have no conflict of interest.
Ethical approval This procedure was in accordance with ethical standards of institutional research committee and with 1964 Helsinki declaration and its amendments or comparable ethical standards.

Informed consent All individuals have individual rights that are not infringed. Informed consent was obtained from all individual participants included in the study.

\section{References}

1. Moriya Y (1993) Pelvic node dissection with autonomic nerve sparing for invasive lower rectal cancer: Japanese experience. In: Wanebo HJ (ed) Colorectal cancer. Mosby Year Book, St. Louis, pp 274-289

2. Havenga K, Maas CP, DeRutier MC, Welvaart K, Trimbos JB (2000) Avoiding long-term disturbance to bladder and sexual function in pelvic surgery, particularly with rectal cancer. Semin Surg Oncol 18:235-243

3. Leroy J, Henri M, Rubino F et al (2006) Sigmoidectomy. In: Milsom J, Böhm B, Nakajima K (eds) Laparoscopic colorectal surgery. Springer, New York, pp 145-169

4. Jayne DG, Brown JM, Thorpe H, Walker J, Quirke P, Guillou PJ (2005) Bladder and sexual function following resection for rectal cancer in a randomized clinical trial of laparoscopic versus open technique. Br J Surg 92:1124-1132
Electronic supplementary material The online version of this article (doi:10.1007/s10151-016-1574-8) contains supplementary material, which is available to authorized users.

C. G. S. Huscher

cristiano.huscher@gmail.com

1 Department of Surgical Oncology, Rummo Hospital, Benevento, Italy

2 Department of Surgery, Kantonsspital St. Gallen, St. Gallen, Switzerland 